\title{
La globalización, el Derecho Internacional y el sistema interamericano de Derechos Humanos*
}

\section{Globalization, International Law and the Inter-American Human Rights system}

Fecha de aprobación: 7 de agosto de 2009 Fecha de recepción: 23 de septiembre de 2009

Jorge Carvajal ${ }^{* *}$

\section{Resumen}

A lo largo del texto se analizará la relación entre globalización, sistema interamericano de Derechos Humanos y democracia. Se hará énfasis en la última década del siglo XX, momento que se caracteriza por la implementación del proceso de globalización, el cual promovió el discurso de la democracia y los Derechos Humanos como elementos concomitantes con el desarrollo neoliberal. Se mostrarán las contracciones que se han presentado producto de esta relación.

\section{Palabras clave}

Sistema interamericano, democracia, Derechos Humanos, globalización.

\begin{abstract}
Throughout the text we will analyze the relationship between globalization, inter-American system of Human Rights and Democracy. Emphasis will be placed in the last decade of the twentieth century, when charac-

Este artículo de investigación hace parte de la producción del grupo de línea investigación Derecho y Sociedad, de la Facultad de Derecho de la Universidad Santo Tomás, sede Bogotá.

Docente de la Facultad de Derecho de la Universidad Santo Tomás, Doctor en Sociología Jurídica e Instituciones Políticas, Máster en Estudios Políticos del Instituto de Estudios Políticos y Relaciones Internacionales IEPRI-UN, Abogado de la Universidad Nacional y Licenciado en Ciencias Sociales. Correo electrónico: jorgeilsa@hotmail.com, jorgecarvajal@usantotomas.edu.co
\end{abstract}


terized by the implementation of the globalization process, which promoted the discourse of democracy and human rights, as being concomitant with neoliberal development. This displays the contractions that have submitted product of this relationship.

\section{Key words}

American system, democracy, human rights, globalization.

\section{INTRODUCCIÓN}

Desde 1919, con la creación de la Sociedad de las Naciones, el Derecho Internacional público comenzó a tener incidencia en temas relacionados con la protección de los Derechos Humanos. Un aspecto que comenzó a dar relevancia al Derecho Internacional en esta temática fue el relativo a las convenciones firmadas por los Estados sobre materias laborales, las cuales adquirieron obligatoriedad para los Estados signatarios. La obligatoriedad generó un doble resultado, por un lado, los compromisos adquiridos comenzaron a ser parte de la legislación interna y, por otro, los Estados adquirían una responsabilidad internacional cuyo cumplimiento podía ser exigido ante los organismos internacionales (García, 2004, p. 48). A las reglas internacionales del trabajo se sumaron el Derecho Internacional Humanitario y las normas de protección a las minorías.

Con el final de la Segunda Guerra Mundial, el papel del Derecho Internacional Público se acentúo notablemente, como consecuencia de los hechos ocurridos en esta confrontación. Entonces, aparecieron nuevas instituciones como la Organización de Naciones Unidas (ONU), de orden mundial, la cual entre sus funciones tiene proteger y garantizar los Derechos Humanos. Posteriormente, se fortalecieron las organizaciones de orden regional que buscaron fines similares; éste es el caso de la Organización de Estados Americanos (OEA).

En estas condiciones el Derecho Internacional se dotó de una serie de instrumentos jurídicos como la declaración Universal de los Derechos del Hombre de la ONU de 1948; la Convención Americana sobre Derechos Humanos, conocida como Pacto de San José de Costa Rica de 1969, la Carta de Derechos Económicos y Sociales de la ONU de 1966 la Carta Africana de de los Derechos Humanos, en vigencia desde 1986 y recientemente el Estatuto de Roma (1998). Tales reglamentos tienen la vocación de generar una mayor capacidad para hacer respetar los Derechos Humanos. Hoy en día el Derecho Internacional de los Derechos Humanos engloba un conjunto de reglas jurídicas, las cuales con la globalización adquieren mayor peso y protagonismo.

Por tanto, hoy en día existe un claro reconocimiento del Derecho Internacional, en particular de los Derechos Humanos, tanto en el plano nacional como en el plano internacional. En este aspecto es clave el accionar jugado por la ONU, así como por parte de las organizaciones regionales, para nuestro caso la OEA, en la promoción, en el reconocimiento defensa y en el reconocimiento de Ios Derechos Humanos. El Derecho Internacional, con el tiempo, ha adquirido un mayor peso, en la medida en que la jurisdicción internacional se constituye en una expresión institucional de carácter obligatorio y permanente.

Para el caso del continente americano, la OEA se ha propuesto, por medio de la Convención Americana de Derechos Humanos, el respeto y la protección de los Derechos Humanos en la región. En esta convención se establecen los derechos que los Estados deben proteger, así como las instituciones encargadas de exigir dicha protección y medios para acceder a ellas. 
El presente texto analizará la relación que existe entre la globalización, el Derecho Internacional y su expresión en el sistema interamericano de Derechos Humanos. La tesis que se desarrolla plantea cómo la globalización incide en los ordenamientos jurídicos, políticos, sociales y nacionales, al integrar los espacios nacionales, regionales y transnacionales o al intensificar su papel en el escenario jurídico estatal e internacional. Esta situación se da tanto para el Derecho Internacional privado, como para el Derecho Internacional Público.

Con la globalización, el sistema interamericano de protección de los Derechos Humanos entra a jugar un papel más relevante en tres escenarios con diferentes grados de relación. A nivel regional, el sistema interamericano se constituye como un espacio subsidiario al de los propios estudios para la defensa de los Derechos Humanos, con un grado de mayor significación e importancia, ya que va acompañado del discurso por la democracia, interrelacionándose con los demás sistemas de Derecho Público Internacional a través del "Sof Law". En el ámbito nacional existe un reconocimiento de la existencia y validez de la jurisdicción internacional gracias a que el nuevo constitucionalismo entiende que los tratados internacionales se incorporan al Derecho interno como parte o extensión del ordenamiento constitucional ("bloque de constitucionalidad"). Finalmente, se fortalece la idea del pluralismo, al considerar que existen múltiples ordenamientos legales que buscan solucionar conflictos, uno de los cuales lo constituyen precisamente las cortes internacionales. Esta relación se da en tres escenarios: lo nacional, a partir del bloque de constitucionalidad; lo regional, en virtud del reconocimiento del sistema interamericano de Derechos Humanos, y el transnacional visto desde el pluralismo jurídico. Estos escenarios se han visto fortalecidos en razón del fenómeno de la globalización que ha incrementado la interrelación entre ellos mismos.

\section{GLOBALIZACIÓN Y LAS TRANSFORMACIONES DEL DERECHO}

Los efectos de la globalización en el Derecho han sido de enorme importancia. En este nuevo escenario se han generado cambios en la concepción y efectos de lo jurídico. Sin duda, el punto de partida lo constituye el hecho de la transformación del paradigma clásico del Derecho propio del Estado moderno, el cual concebía lo jurídico como un conjunto de normas cuya producción emanaba única y exclusivamente del Estado. Estas normas se organizaban de forma sistemática y su cumplimiento se ejercía de forma coercitiva por quien tenía el monopolio de la fuerza pública. Para esta concepción monista del Derecho, el Estado era el único escenario propio y excluyente en la creación de la norma jurídica. Esta concepción lo entendió así desde el inicio del Estado moderno a finales del siglo XVIII, hasta las postrimerías del siglo XX y se sustentó en la teoría liberal clásica (Santos, 1998, p. 19).

Las dos últimas décadas del siglo XX significan un giro trascendental a la interpretación monista del Derecho. El fenómeno de la globalización estimuló la idea de un pluralismo jurídico, tanto dentro de los Estados, como en el marco de las relaciones internacionales. Este pluralismo ha defendido la tesis de la coexistencia de diferentes ordenamientos jurídicos, tanto locales como transnacionales, que entran a complementar y, en algunos casos, a rivalizar con el ordenamiento jurídico estatal. Esta concepción cuestionó al Estado como creador único del Derecho, demostrando que existe toda una normatividad por fuera y al margen del Estado nacional.

El pluralismo jurídico es un fenómeno que aflora con la globalización, esto es, que no es algo nuevo. En verdad, lo que había venido ocurriendo era que el Estado moderno había buscado suprimir los ordenamientos jurídicos existentes por fuera de él. 
El caso más notable fue la exclusión decretada a los sistemas normativos de los pueblos indígenas en América durante los siglos XIX y XX, bajo la idea de incorporación de dichos pueblos a la "civilización occidental" bajo un único ordenamiento jurídico como sinónimo de civilización y modernidad (Ardila, 2002, pp. 51 y ss.).

Por otra parte, en el ámbito global aparecieron una serie de actores que promovieron la existencia de marcos jurídicos transnacionales y de espacios de solución de conflictos internacionales. Es así como en el ámbito del comercio mundial y del movimiento de capitales las diferencias que pueden surgir entre empresas o entre éstas y los Estados, buscan resolverse mediante la intervención de instituciones como el $\mathrm{CIADI}^{1}$ y el Sistema de Solución de Diferencias de la OMC². Este tipo de espacios harán parte del campo de la "lex mercatoria" o del Derecho Internacional Privado, el cual recibe un mayor énfasis a partir de la década del noventa, como factor que acompaña los procesos de internacionalización de las economías bajo la égida de las corrientes neo-liberales.

Otro escenario del Derecho que se intensifica con la globalización es el relacionado con el campo de los Derechos Humanos, el cual se introduce como paradigma que marca las relaciones entre los Estados acompañado de un discurso en pro de la democracia política. A partir de la década del noventa la agenda de los Derechos Humanos comenzó a tener mayor incidencia en el ámbito nacional e internacional, sobre todo, en un escenario

1 CIADI es el centro internacional de arreglo de diferencias relativas a inversión. Hace parte del Banco Mundial y aparece en 1965 en la convención de Washington D.C. Inicialmente, hicieron parte de él 140 naciones. Es una institución que se encarga de la resolución de conflictos entre Estados, Estado y un particular o entre el Estado y un inversionista.

2 El sistema de solución de diferencias de la Organización Mundial del Comercio tiene como antecedente el acuerdo de Bretton Wood de 1944, que dio origen al Banco Mundial, al Fondo Monetario Internacional, al gatt, antecedente de la Organización Mundial del Comercio (OMC). de transición política que implicaba la democratización de muchas sociedades después de largos periodos de dictaduras. Ello condujo a los gobiernos a la formulación de plataformas claras de titularidades desde los Derechos Humanos; reformas a las instituciones políticas y la revalorización los organismos de carácter internacional dedicados a la aplicación del Derecho Internacional. Por tanto, las cortes internacionales de Derechos Humanos comenzaron a tener un mayor papel protagónico a nivel global.

Estos cambios tuvieron expresiones concretas en América Latina. El Derecho acompañó profundas transformaciones en los textos constitucionales y normativos. La mayoría de las constituciones de los países de América Latina reconocen en la actualidad la importancia de los derechos civiles y políticos y los derechos económicos sociales y culturales. De igual manera, dichos textos legales han incorporado a diferentes sujetos sociales como titulares de derechos específicos (pueblos indígenas, niñez, mujeres, comunidades afroamericanas, minorías sexuales, etc.).

\section{LAS NUEVAS CONSTITUCIONES, LA DEMOCRACIA Y EL DERECHO INTERNACIONAL}

En la década del noventa, en América Latina las reformas se orientaron a reconstruir y a profundizar la democracia política; sin embargo, este propósito, en alguna medida, terminó frustrándose, pues coincidió con las llamadas "políticas de ajuste económico", impulsadas por las corrientes neoliberales en auge.

Entre 1980 y 1990, se presentaron diecisiete reformas constitucionales en América Latina ${ }^{3}$. La mayo-

3 Ente 1980 y 1995 once países latinoamericanos adoptaron nuevas constituciones, Chile (1980), Honduras (1982), El Salvador (1983), Guatemala (1985), Brasil (1988), Colombia (1991), Paraguay (1992), Perú (1993), Panamá (1994), Argentina (1994) y Nicaragua (1995). Adicionalmente, en Venezuela, México, Ecuador, Costa Rica, Bolivia y Uruguay se presentaron importantes reformas constitucionales. 
ría de ellas como producto de la transición hacia la democracia o con miras a su fortalecimiento. Las nuevas constituciones incorporaron al Derecho interno la normatividad internacional de los Derechos Humanos y consagraron nuevas titularidades e instituciones para la protección y cumplimiento de esos derechos. En adelante, el Derecho Constitucional adquirió una mayor relevancia en los ámbitos jurídicos, académicos y sociales.

Los movimientos sociales se inspiraron en estos procesos y construyeron un discurso ligado a las nuevas formas de participación ciudadana, una nueva lectura de los derechos desde reivindicaciones sociales, culturales y de identidad, cargado de un fuerte optimismo frente a los mecanismos de exigibilidad jurídica. El optimismo del movimiento social fue reforzado por un sector intelectual que veía en el nuevo constitucional un potencial emancipador.

"El nuevo constitucionalismo latinoamericano" -como ha sido denominado- propició, a partir de los años noventa, la idea que era posible un cambio social a través del Derecho. Esta percepción se acompañó de una sobre valorización de las nuevas instituciones, en particular de aquéllas que representaban un giro en la administración de justicia, como los tribunales internacionales, las defensorías del pueblo y el Derecho Internacional de los Derechos Humanos. Esta corriente generó un discurso que promovía el respeto y el cumplimiento de los Derecho Humanos. Por su parte, los Estados, a través de la firma de los tratados sobre Derechos Humanos, aceptaban la obligación hacer compatible el derecho interno con el Derecho Internacional.

Lo que está en el debate durante los años 90 es una reforma del Estado en sus dimensiones políticas e institucionales, de acuerdo a demandas de democratización y de modernización. Las primeras aspiran a una participación social que vayan más allá de las puras formas electorales y al desarrollo de una institucionalidad estable. Las segundas surgen a partir de la vocación internacional que se afirma en todos los ámbitos de la sociedad. Esta modernización institucional del Estado parece ser una condición de viabilidad para la consolidación de las reformas económicas que ya están en curso (Muñoz, p. 1993, p. 25).

En América Latina, el sistema interamericano de Derechos Humanos comenzó a jugar un papel mucho más relevante que el pasado, en la medida en que los escenarios de transición a la democracia y el fortalecimiento de los regímenes políticos de los Estados de la región abrían las puertas para que la Comisión Interamericana de Derechos Humanos y la Corte Interamericana de Derechos Humanos jugaran un papel más decisivo en la defensa de los Derechos Humanos como condición para la vigencia plena de la democracia en el continente.

\section{EL SISTEMA INTERAMERICANO Y EL DERECHO INTERNACIONAL EN LA GLOBALIZACIÓN}

En el marco de la mundialización, los sistemas internacionales de justicia impactaron en la sociedad. Varios elementos de los ya señalados generaron como resultado un mayor reconocimiento de estas instancias, hablamos de los procesos de democratización, la mayor interdependencia generada por los procesos globales y el nuevo constitucionalismo que promovió con más fuerza la defensa de los derechos fundamentales y el reconocimiento de los tratados internacionales como parte del ordenamiento interno.

La aceptación por los Estados de los distintos medios normativo-jurídicos e institucionales, por fuera de los marcos nacionales, produjo un giro sustancial en el entendimiento del Derecho. Frente a esta nueva realidad, señala el ex juez Cançado Triado, de la Corte Interamericana de Derechos Humanos, cómo ha evolucionado la jurisdicción internacional. En la actualidad, no existe duda acerca de su carácter obligatorio y permanente de la accesibilidad a estas instancias de cualquier persona que considere 
vulnerados sus derechos por parte de su Estado. En el plano internacional es evidente la existencia de diversas instituciones:

[...] todos los Estados miembros del Consejo de Europa son hoy parte en la convención Europea de Derechos Humanos y la Corte Europea de Derechos Humanos, a la cual tienen acceso directo los individuos. Cuenta con jurisdicción obligatoria y automática vis-à-vis todos los Estados Partes.

Del mismo modo, el Tribunal de Luxemburgo tiene jurisdicción obligatoria en relación con todos los Estados miembros de la Unión Europea (UE). Todos los Estados miembros de la Organización de la Unidad Africana (OUA) son hoy parte en la Carta Africana de Derechos Humanos y de los Pueblos, y han decidido (mediante la adopción del Protocolo de Burkina Faso de 1998) establecer una Corte Africana de Derechos Humanos y de los Pueblos; y el 01 de julio de este año el Estatuto de Roma de 1998 sobre el establecimiento del Tribunal Penal Internacional entró en vigor, estableciendo una jurisdicción penal internacional permanente, obligatoria para todos los Estados Partes.

Todos estos ejemplos apuntan inequívocamente en la misma dirección: la jurisdiccionalización de los mecanismos internacionales de protección de los derechos de la persona humana, así como la centralidad de estos últimos en el derecho internacional de este inicio del siglo XXI. Tales desarrollos han sido posibles gracias, en última instancia, al grado más elevado de evolución que ha alcanzado la conciencia humana en nuestros tiempos (Cançado, 2002, p. 67).

De lo anterior se deduce que el Derecho Internacional Público con la globalización ha impulsado al sistema internacional de protección de los Derechos Humanos, que tiene como objetivo garantizar proteger a las personas de posibles abusos de los Estados, tal y como se ha establecido por la Corte Interamericana: "Ios tratados de derechos humanos no se contraen a definir el intercambio entre éstos, sino sirven al fin de proteger los derechos fundamentales de los seres humanos frente a su propio Estado y ante los otros Estados contratantes $^{\prime 4}$

Cuando hablamos del sistema interamericano, es necesario establecer que se accede a ella sólo de manera subsidiaria. En el marco normativo del sistema interamericano, el acceso a la justicia se encuentra consagrado en el artículo 8.1 del Pacto de San José de Costa Rica en el que se dispone:

Toda persona tiene derecho a ser oída, con las debidas garantías y dentro de un plazo razonable, por un juez o autoridad competente, independiente e imparcial, establecida con anterioridad por la ley, en la sustanciación de cualquier acusación penal formulada contra ella, o para la determinación de sus derechos y obligaciones de orden civil, laboral, fiscal o de cualquier otro carácter.

En relación con el tema de acceso a la justicia interamericana la Convención Americana de Derechos Humanos señala en el artículo 25 que:
1. Toda persona tiene derecho a un recurso sencillo y rápido o a cualquier otro recur- so efectivo ante los jueces o tribunales competentes, que la ampare contra actos que violen sus derechos fundamentales reconocidos por la Constitución, la ley o la presente Convención, aun cuando tal violación sea cometida por personas que actúen en ejercicio de sus funciones oficiales.

\section{Los Estados Partes se comprometen:}

a) a garantizar que la autoridad competente prevista por el sistema legal del Estado decidirá sobre los derechos de toda persona que interponga tal recurso;

b) a desarrollar las posibilidades de recurso judicial, $y$

c) a garantizar el cumplimiento, por las autoridades competentes, de toda deci-

4 Corte IDH, Control de Legalidad en el Ejercicio de las Atribuciones de la Comisión Interamericana de Derechos Humanos (Arts. 41 y 44 a 51 de la Convención Americana sobre Derechos Humanos). Opinión Consultiva OC-19/05 del 28 de noviembre de 2005. Serie A, No.19, párr. 21. 
sión en que se haya estimado procedente el recurso.

Como se observa de los artículos señalados, el acceso está estrechamente vinculado con la administración de justicia y al uso de recursos adecuados para llegar a la solución de una controversia. Ahora bien, poder acceder a estas instancias internacionales, en particular al sistema interamericano, ha posibilitado fortalecer la democracia y evitar la impunidad por violación a los Derechos Humanos en la región.

Durante los procesos de transición a la democracia, buena parte de los Estados latinoamericanos optaron por el perdón y olvido, frente a la opción de conocer la verdad y hacer justicia. En este escenario se enfrentaron a los dilemas propios que necesariamente surgen en los procesos de justicia y reconciliación en periodos de posconflicto o de transición a la democracia (Orozco, 2002, p. 78). Las organizaciones de víctimas y las organizaciones gubernamentales de Derechos Humanos han cuestionado los procesos de perdón y olvido, porque consideran que generan impunidad frente a las graves violaciones de Derechos Humanos cometidas por los regímenes dictatoriales (Miranda, 1999, p. 81). En los procesos de transición a la democracia acaecidos en casi todos los países de la región desde mediados de la década del ochenta, el derecho de las víctimas a la verdad, la justicia y la reparación fue desconocido y, por tanto, los estrados internacionales se convirtieron en el instrumento para evitar la total impunidad.

La Corte ha buscado poner fin a las auto amnistías decretadas por las dictaduras militares para permitir el retorno a la democracia, las cuales han impedido las investigaciones por violación a los Derechos Humanos y el castigo a los responsables.

En su voto razonado en el caso en cuestión, el entonces Presidente de la Corte, Juez Antônio A. Cançado Trindade, señaló que:
Las llamadas autoamnistías son, en suma, una afrenta inadmisible al derecho a la verdad y al derecho a la justicia (empezando por el propio acceso a la justicia). Son ellas manifiestamente incompatibles con las obligaciones generales -indisociables- de los Estados Partes en la Convención Americana de respetar y garantizar los derechos humanos por ella protegidos, asegurando el libre y pleno ejercicio de los mismos (en los términos del artículo 1(1) de la Convención), así como de adecuar su derecho interno a la normativa internacional de protección (en los términos del artículo 2 de la Convención). Además, afectan los derechos protegidos por la Convención, en particular los derechos a las garantías judiciales (artículo 8) y a la protección judicial (artículo 25). Naciones Unidas, Declaración y Programa de Acción de Viena (1993), Parte II, párr. 60 (Ventura, 2007, p. 354).

Por tanto, se evidencia la importancia cada vez mayor de los estrados internacionales vinculada a las transformaciones del Derecho Internacional Humanitario que lo convierte en una de las áreas más significativas de su derecho globalizado. Para el caso de nuestro continente, el Sistema Interamericano de Derechos Humanos, el cual es expresión institucional de la defensa de dichos derechos. Esta valoración es importante y ha sido catalogado como uno de los aspectos más relevantes del sistema por parte de un grupo de ONG que litigan ante éste y que así lo expresaron en una declaración, a propósito de la celebración de los 40 años de la Convención Americana y sus órganos de protección. En dicha declaración expresan:

En épocas de dictaduras, guerras civiles y gobiernos autoritarios, la existencia del Sistema Interamericano permitió juzgar abusos que de otra forma la justicia hubiera olvidado; ayudó a superar la impunidad de algunos criminales y obtuvo la reparación y el reconocimiento para miles de víctimas. A él acudieron con desesperación quienes no encontraban justicia en sus países. Los órganos de protección contribuyeron de manera significativa a allanar caminos hacia el desarrollo del 
Estado de Derecho en gran parte del hemisferio (Intervención de la coalición internacional de ONG, 2009, p. 1).

La Convención Americana de Derechos Humanos entró en vigor en 1978 y ha sido ratificada por veinticinco países de la región: Argentina, Barbados, Brasil, Bolivia, Chile, Colombia, Costa Rica, Dominica, República Dominicana, Ecuador, El Salvador, Granada, Guatemala, Haití, Honduras, Jamaica, México, Nicaragua, Panamá, Paraguay, Perú, Surinam, Trinidad y Tobago, Uruguay y Venezuela. La Convención define los Derechos Humanos que Ios Estados se comprometen internacionalmente a respetar y a ofrecer las garantías suficientes para que sean respetados; establece los mecanismos de acceso, el procedimiento y las instituciones responsables del cumplimiento de la Convención.

La Comisión Interamericana de Derechos Humanos y la Corte Interamericana de Derechos Humanos no sólo se han convertido en instituciones ante las cuales pueden acudir las víctimas para enfrentar a un Estado que ha vulnerado sus derechos fundamentales consagrados en la convención, sino que también se puede acudir a estas instancias en demanda de protección de la víctimas por medio de medidas cautelares y provisionales. En este aspecto señala el juez García Ramírez: "la víctima se plantea con fuerza, como sujeto del Derecho internacional, titular de derechos de esta naturaleza, cuando se le reconoce la facultad de enfrentar a un Estado en una instancia internacional, llamada a resolver en definitiva" (García, 2002, p. 3).

\section{EL SISTEMA INTERAMERICANO DE DERECHOS HUMANOS Y LA CRISIS DE LA DEMOCRACIA EN AMÉRICA LATINA}

A pesar de los procesos de democratización experimentados en América Latina en las últimas décadas, la región muestra, con todo, demasiadas debilidades e imperfecciones de sus sistemas democráticos, agravado desde hace cerca de veinte años por el refortalecimiento de la institución presidencial y por las pretensiones de los presidentes de casi todos los países a buscar sucesivas reelecciones. Es lo que ha dado en llamarse, a través de un concepto impreciso, "el neo-presidencialismo" latinoamericano. El fenómeno conducido a desarticular el modelo del Estado de derecho en sus rasgos esenciales: separación de las ramas del poder; periodicidad de los mandatos; principio de legalidad preexistente a los gobernantes y respeto y garantía de los derechos fundamentales.

La crisis del Estado de derecho, que en ultimas termina por afectar el sistema democrático mismo, se conjuga con la pérdida de garantías sociales concomitante con el proceso neoliberal global que promueve nuevas formas de excepcionalidad, esta vez a través del discurso de la seguridad que se torna hegemónico. Desde los primeros años de la década del noventa, se fueron construyendo diversas agendas de seguridad: la seguridad humana, la seguridad frente a distintas amenazas del terrorismo y la seguridad individual. En la actualidad esta agenda en muchos casos termina por restringir las garantías y el respeto de los Derechos Humanos (Carvajal, 2008, pp. 5 y ss.). En los comienzos del siglo XXI, nos encontramos en un escenario en el cual la democracia formal protege más los intereses del mercado que los Derechos Humanos de las personas al amparo del discurso de la seguridad.

En este aspecto compartimos la tesis que planteada por Óscar Mejía, quien afirma que existe una estrecha relación entre el modelo económico neoliberal y la democracia formal: "Tenemos entonces que el proyecto político del neoliberalismo configura la democracia como una democracia capitalista, expropiada de sus dimensiones utópicas y normativas en nombre del mercado y de la eficiencia" (Mejía \& Jiménez, 2006, p. 14). A lo político se le despoja de su para determinar el rumbo de la economía; por tanto, se presenta una subordinación de la política a las directrices económicas. "El problema de la gobernabilidad, la eficiencia y la estabilidad política se superpo- 
nen a las lógicas participativas, incluyentes de las auténticas democracias participativas" (Mejía \& Jiménez, 2006, p. 24).

La ideología de la "seguridad", como representación del capitalismo neoliberal, socavará los valores políticos e ideológicos sobre los cuales se había fundamentado la agenda de posguerra fría en el ámbito mundial, en particular, en lo relacionado con la idea de los Derechos Humanos y la democracia como referente ético, político y social. La ideología de la seguridad fue construyendo una agenda orientada a cuestionar la idea de los Derechos Humanos y la democracia como límite del poder global, en particular, la garantía de esos derechos. Este pensamiento encuentra un amplio apoyo social, ya que estará acompañado de la idea de lucha contra toda forma de terrorismo.

Esta situación ha tenido incidencia en el sistema interamericano. Desde 1965, la Comisión Intera- mericana de Derechos Humanos fue autorizada expresamente a recibir y procesar denuncias o peticiones sobre casos individuales en los cuales se alegaban violaciones a los Derechos Humanos. Entre 1965 y 1997 se recibieron cerca de 12.000 peticiones, es decir, en un periodo de 32 años el promedio de peticiones fue de 375 por año, ( $\mathbf{w w w}$. cidh.org/que.htm). Con el retorno a la democracia constitucional en la mayoría de los países de América Latina se esperaría que las peticiones disminuyeran. Sin embargo, no ha ocurrido así; para el periodo 1997 a 2008, el número de peticiones fue de 12.712. El promedio de peticiones en los últimos once años ha sido de 1.155, es decir, se presentó un incremento del $300 \%$ en relación con los primeros treinta y dos años de funcionamiento del sistema de protección. Los resultados finales publicados en relación con estos casos se pueden encontrar en los informes anuales de la Comisión país por país.

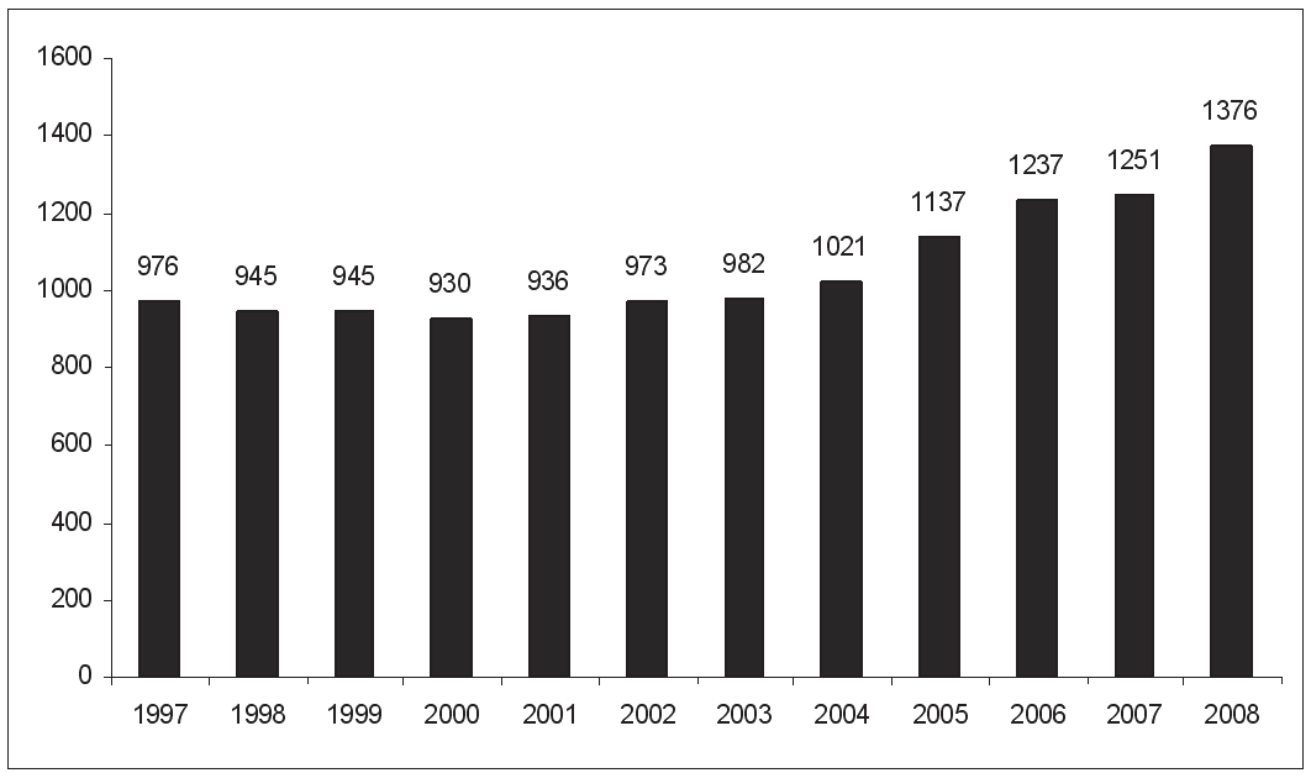

Gráfica 1. Total de casos y peticiones en trámite por año recibidas por la Comisión Interamericana de DDHH entre 1997 y 2008

Fuente: www.cidh.org/annualrep/2008sp/cap3.sp.htm 


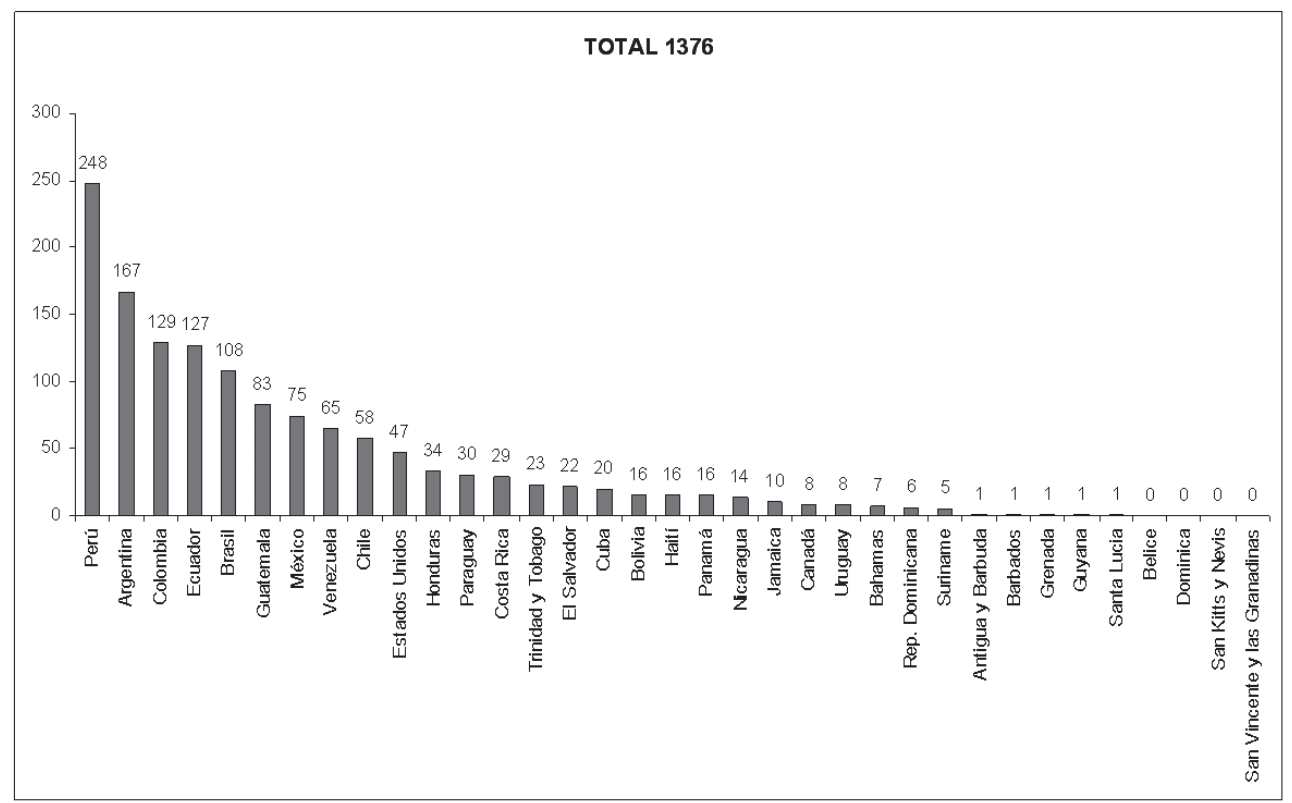

Gráfica 2. Peticiones realizadas al sistema interamericano por país en el 2008

Fuente: www.cidh.org/annualrep/2008sp/cap3.sp.htm

Existe una relación directa entre régimen político y su incidencia en el sistema interamericano. El sistema interamericano de Derechos Humanos se enfrenta a escenarios políticos que terminan por afectar su funcionamiento y el acceso a la justicia. En este aspecto encontramos dos periodos que quisiéramos resaltar: el sistema ante las transiciones a las democracias en América Latina y el sistema ante los nuevos regímenes políticos.

En cuanto al trabajo del sistema frente a los procesos de transición, se encuentran una serie de elementos propios de estos periodos, caracterizados por negociaciones entre los gobiernos dictatoriales y los partidos políticos que abordaban temas como el tratamiento a la víctimas, los procesos de amnistía e indulto de los antiguos detentadores del poder y el nuevo modelo de gobierno que se establecería una vez entregado el poder por parte de los primeros.

Una vez cumplida la transición y la entrega del poder a los civiles, los nuevos gobiernos se ocuparon de la construcción de mecanismos de reconciliación nacional, entre éstos se encuentran las llamadas "Comisiones de la Verdad", las cuales, entre otros aspectos, buscaron establecer los impactos que sobre la población civil habían generado los gobiernos de facto y las guerras internas. Sin embargo, las comisiones de la verdad no tocaron temas relacionados con la justicia, pues la mayoría de éstas solamente pretendían establecer la verdad histórica de lo ocurrido durante las dictaduras.

En la mayoría de los casos, la normatividad pactada con los anteriores detentadores del poder desembocó en leyes de amnistía e indulto y en regímenes democráticos que no tocarían a los violadores de Derechos Humanos. Lo anterior ocasionó un alto grado de impunidad y escepticismo frente a los sistemas de justicia nacionales, obligando a organizaciones de víctimas y ONG a buscar una salida en los estrados internacionales; lo cual implicó un fortalecimiento del sistema interamericano en respuesta a la impunidad que ofrecieron Ios Estados nacionales. En esta etapa (1980-1990), 
el sistema interamericano adquirió un importante reconocimiento por parte de las organizaciones de víctimas y servicios legales que acudieron ante éste en demanda de justicia y reparación que les fue negado en sus propios países.

Desde 1978, las leyes de impunidad proliferaron en los países de Centro y Suramérica, los cuáles han sufrido largos periodos de violencia política y violación sistemática de los derechos humanos por parte del Estado. Esas leyes tomaron la forma de amnistía, prescripción e indulto, reconociendo la obediencia debida como una defensa para los crímenes cometidos por agentes del gobierno. El propósito de estas leyes ha sido el de prevenir la investigación y el castigo de graves violaciones de los derechos humanos.

Ante la imposibilidad de obtener justicia en sus países, muchas personas y organizaciones no gubernamentales ha[n] recurrido a instituciones internacionales, tanto regionales como internacionales, para intentar revertir una situación que notoriamente contradecía las obligaciones internacionales contraídas por los Estados. Es acá, donde surge la importancia de las investigaciones, fallos y decisiones de los organismos regionales de protección de los derechos humanos, tales como la Corte y la Comisión Interamericanas de Derechos Humanos (Ventura, 2007, p. 349).

Una vez consolidados los regímenes democráticos se creería que el número de peticiones ante el sistema interamericano disminuirían; sin embargo, esta tendencia no ha disminuido; por el contrario, existe un incremento notable de demandas ante el sistema; ello nos conduce a una pregunta que se encuentra por fuera mismo del sistema y es relativo al déficit de democracia o a la ausencia de una política consistente en materia de Derechos Humanos por parte de los Estados signatarios de la Convención Americana. En todo caso, sea cual fuere la explicación, la situación tiene como denominador común, frente al periodo de transición, el alto grado de impunidad presente en los países de América Latina.
A comienzos del siglo XXI, el panorama político que presenta la región no es el más alentador para el cumplimiento y materialización de los Derechos Humanos. Una de las características de los sistemas políticos de la región es el surgimiento de sistemas políticos neo-presidenciales que tienden a concentrar el poder y producir medidas de excepción. Esta situación afecta al sistema interamericano que fue creado a fin de fortalecer la democracia y proteger los Derechos Humanos. En el caso de Estados regidos por principios democráticos se tendrá mayor voluntad para apoyar a los organismos de protección del sistema interamericano y atender sus recomendaciones y cumplir sus decisiones judiciales. Por el contrario, un Estado de corte autoritario verá con desgano estas instancias internacionales.

La voluntad de los Estados uno a uno, como grupos o como gran conjunto, es factor y fortaleza de la corte. Lo ha sido para su creación y paulatino desarrollo. Pero esa misma voluntad puede ser adversa, será disuasiva o debilitadora de la jurisdicción interamericana (García, 2001, p. 556).

Un elemento que en la actualidad ejerce un importante peso para el respeto y cumplimiento de los Derechos Humanos y que está jugando un papel crucial/ en el continente americano es el tema de la seguridad. En muchas ocasiones, la agenda de la seguridad entra a limitar gravemente los Derechos Humanos (Carvajal, 2008, p. 10). En estos casos los Estados se escudan con la tesis de la soberanía nacional, frente a la justicia internacional para eludir su intervención. Sin embargo, esta situación ha sido analizada por la Corte Interamericana de Derechos Humanos, la cual establece precisos límites a los Estados de excepción y a las medidas restrictivas de los derechos que pueden adoptar los Estados durante tales periodos (García, 2001a, p. 660). 


\section{CONCLUSIÓN}

Es importante señalar como conclusión que, a pesar del escenario relativamente sombrío de la política regional, un elemento positivo resulta ser la evolución que han tenido los Derechos Humanos como corpus juris universal y su inclusión en la agenda de las relaciones entre los Estados. El papel cada vez más decidido y protagónico de las cortes internacionales contribuye decisivamente no sólo a la justicia y reparación de las víctimas de violaciones a los Derechos Humanos, sino que también se convierte en un instrumento de presión de la propia comunidad internacional para condenar y prevenir tales violaciones por parte del Estado.

\section{REFERENCIAS}

Ardila, E. (2002). Pluralismo jurídico y alternatividad judicial. Otro Derecho, 26-27.

Cançado, A. (2002). El derecho de acceso a la justicia internacional y las condiciones para su realización en el sistema interamericano de protección de los Derechos Humanos. Revistas IIDH.

Cançao, A. \& Ayala, C. (1999). Eficacia jurídica de las resoluciones de la comisión y corte interamericana de derechos humanos y su comparación con otros sistemas. En J. Carvajal (2008). La seguridad en el Estado de garantías. Bogotá, Colombia: Instituto Latinoamericano de Servicios Legales Alternativos ILSA.

García R., S. (2002). El acceso de la víctima a la jurisdicción internacional sobre derechos humanos. En A. García (2004). Los derechos humanos en el derecho internacional. Bogotá: Derechos Humanos en Colombia 25 años Itinerario de una
Historia-comité Permanente por la Defensa de los Derechos Humanos.Bogotá, Colombia.

http://www.iidh.ed.cr/BibliotecaWeb/PaginaExterna. aspx?Comunidad $=246 \& T i p o=565 \& U R L=$ $\% 2$ fBibliotecaWeb\%2fVarios\%2fDocumento s\%2fMaterial_Educativo\%2fEficacia_Juridica. htm\&Barra=1\&DocID=2980. Recuperado el 2 de julio de 2009.

http://www.iidh.ed.cr/BibliotecaWeb/PaginaExterna.aspx?url=/BibliotecaWeb/Varios/Documentos/ Material_Educativo/Acceso_victima_jurisdiccion. htm Recuperado el 2 de julio de 2009.

Mejía Q., O. \& Jiménez, C. (2005). Nuevas teorías de la democracia. De la democracia formal a la democracia deliberativa. Revista Colombia Internacional, 62, 12-31.

Miranda, J. (1999). Enfoques de Naciones Unidas sobre impunidad y reparación. En Verdad y Justicia, procesos de paz y transición a la democracia. Bogotá, Colombia.

Muñoz, O. (1993). Después de las privatizaciones, hacia el estado regulador. Chile: CIEPLAN.

Orozco, I. (2002). Posguerra en Colombia: divagaciones sobre la venganza, la justicia y la reconciliación. Revista Análisis Político, 46.

Santos, B. (1998). La globalización del derecho. Bogotá, Colombia: Instituto Latinoamericano de Servicios Legales Alternativos, ILSA.

Ventura R., M.E.(2007). Estudios sobre el sistema interamericano de protección de los derechos humanos. San José de Costa Rica. 